\title{
Tracing the Himalayan erosion and weathering products in the Equatorial Indian Ocean using sedimentary lead isotopes
}

\author{
N. P. SUKUMARAN* \\ CSIR-National Geophysical Research Institute, Hyderabad, \\ INDIA- 500007 \\ *(correspondence: npsukumaran@ngri.res.in)
}

Our understanding of a Himalayan sourced lead $(\mathrm{Pb})$ to the northern Indian Ocean (north of $20^{\circ} \mathrm{S}$ ) has largely been known from seawater archives of Fe-Mn crusts and nodules, while $\mathrm{Pb}$ isotope records of detrital sediments of continental detritus are entirely lacking. I present here the first measurements of high-precision $\mathrm{Pb}$ isotopes performed in the pelagic clays of two sediment cores (AAS-40/GC02 and AAS-27/GC01) raised from the Central Indian Basin (CIB). Analyses were performed using ${ }^{205} \mathrm{Tl} / 203 \mathrm{Tl}$ spike to correct for internal mass bias on Multiple-collector ICPMS with an external precision better than 200ppm $(2 \sigma)$.

Measured $\mathrm{Pb}$ isotopic compositions of the clays span a wide range from 18.10 to 20.08 for ${ }^{206} \mathrm{~Pb} /{ }^{204} \mathrm{~Pb}, 15.61$ to 15.98 for ${ }^{207} \mathrm{~Pb} /{ }^{204} \mathrm{~Pb}$ and 38.13 to 40.39 for ${ }^{208} \mathrm{~Pb} /{ }^{204} \mathrm{~Pb}$. These variations are much larger than the variations that have been recorded in the long-term evolution of $\mathrm{Pb}$ isotopes in the $\mathrm{Fe}$ Mn crusts (\#SS 663) and the surface scrapings of Mn nodules from the CIB. The presence of more radiogenic signatures reflects a strong continental imprint of erosional sources to the CIB. In both $\mathrm{Pb}$ spaces $\left({ }^{206} \mathrm{~Pb} /{ }^{204} \mathrm{~Pb}\right.$ vs ${ }^{207} \mathrm{~Pb} /{ }^{204} \mathrm{~Pb}$ and ${ }^{206} \mathrm{~Pb} / 204 \mathrm{~Pb}$ vs ${ }^{208} \mathrm{~Pb} /{ }^{204} \mathrm{~Pb}$ ), the CIB clays lie along a fairly elongated and positively correlated linear arrays with more radiogenic values similar to the Ganges river sediments of the Himalayas and the unradiogenic to possible magmatic/volcanic source. Simple isotope mass balance calculations based on two end-member mixing reveals that more than $80 \%$ of the clays have been sourced from the Himalayas to the CIB. 